\title{
Exhibit B: Performance entre racismo e antirracismo $^{1}$
}

\section{Exhibit B: Performance between racism and anti-racism}

Francielly Rocha Dossin ${ }^{2}$ 


\section{Resumo}

O presente artigo busca compreender as estratégias visuais da performance intitulada Exhibit B cuja apresentação, agendada para fevereiro de 2016 em São Paulo, foi cancelada. A performance do artista sul-africano Brett Bailey é composta por tableaux vivants (quadros vivos) nos quais atores encenam quadros inspirados em eventos traumáticos do colonialismo e do racismo ocidental. A performance se apresentava como um trabalho antirracista e no entanto, movimentos negros a consideraram o inverso. Com apoio da literatura pós-colonial, em especial a reflexão de Stuart Hall sobre contra-estratégias que buscam minar o regime de representação racializado, procuraremos entender as disputas em torno dessa performance.

Palavras-chave: Exhibit B; Brett Bailey; performance; racismo; antirracismo

\section{Abstract}

This article aims to understand the work "Exhibit B", a performance scheduled to be played in Brazil, but canceled after protests. This performance by South African artist Brett Bailey is composed of tableaux vivants in which actors play out scenes inspired by the traumatic events of colonialism and Western racism. Regardless "Exhibit $B$ " be defined as an anti-racist artwork, black movements considered it the reverse. We'll seek to understand the disputes over this performance with the support of postcolonial literature, especially the reflection of Stuart Hall on counter-strategies in the racialized regime of representation.

Keywords: Exhibit B; Brett Bailey; performance; racism; anti-racism
ISSN: 1414.5731

E-ISSN: 2358.6958

\footnotetext{
1 Este artigo foi parte da tese "Entre evidências visuais e novas histórias: sobre descolonização estética na arte contemporânea" defendida em abril de 2016 no Programa de Pós-Graduação em História da Universidade Federal de Santa Catarina sob orientação da professora Dra. Maria Bernardete Ramos Flores. Sua realização só foi possível graças ao suporte da orientação, do Programa e do apoio financeiro da CAPES (através das bolsas REUNI, Doutorado Sanduíche no Exterior - PDSE, e do Programa de Demanda Social - DS).
}

2 Doutora em História pela Universidade Federal de Santa Catarina. Brasil. frandossin@gmail.com 
Em matéria do jornal Folha de São Paulo, do dia dois de fevereiro de 2016, que trata da diminuição de atrações na Mostra Internacional de Teatro de São Paulo, MITsp, lemos sobre a supressão da performance Exhibit B. Em entrevista ao jornal, o artista Brett Bailey afirma que a organização do festival teria cedido à pressão dos ativistas e ficado receosa de uma possível publicidade negativa. Antônio Araújo, o curador do evento, confirma que o recuo foi feito após o MITsp ser informado do risco de que ativistas "usassem o próprio corpo" contra quem tentasse entrar no teatro, e afirmou: "[...] eu não bancaria o risco de ver a polícia reprimindo negros com violência. Acho que essa é uma das grandes tragédias desse país. $E$ ter qualquer chance de ameaça policial contra negros era um limite para mim" (Araújo apud Fioretti, 2016).

Exhibit $B$ é o título de uma performance-instalação com doze tableaux vivants, (podendo chegar a quatorze, dependendo de cada exibição), onde atores representam quadros inspirados em eventos traumáticos do colonialismo e do racismo ocidental. O artista responsável é o sul-africano Brett Bailey, branco, diretor do grupo Third World Bun Fight, reconhecido pela crítica, e que vem atuando há quase duas décadas. Uma breve pesquisa sobre sua obra revela que sua produção é toda voltada às questões da África colonial e pós-colonial, a exemplo da obra Macbeth, releitura da ópera de Giuseppe Verdi, na qual conta histórias de corrupção entre multinacionais e governantes na República Democrática do Congo.

Já Exhibit $B$ é parte de uma série que vem sendo exposta desde 2010, quando o artista apresentou pela primeira vez Exhibit $A$ em Viena, seguindo posteriormente uma agenda de apresentações por diversas cidades. Quase dois anos depois da primeira montagem, em 2012, em Berlim, a obra começou a ganhar oposição de grupos que a acusaram de racismo. Em setembro de 2014, em Londres após protestos, a performance foi cancelada da programação do festival em que participava. No mesmo ano em Paris, a obra ganhou oposição de proporções semelhantes, entretanto, apesar de ter sua programação alterada em virtude dos protestos, a performance não foi cancelada.

A primeira exibição de Exhibit B na França ocorreu durante o Festival d'Avignon de 2013 onde, segundo a jornalista Bouchez (2014), teve sucesso de público e crítica. A performance reverberou na mídia francesa em novembro de 2014 por conta da polêmica gerada pelos protestos no momento em que ganharia algumas sessões nos espaços do Teatro Gérard-Philippe, em Saint-Denis, um distrito ao norte de Paris, e, em seguida, no Le Centquatre (104), no 19. arrondissement de Paris, onde já tinha sido apresentada no ano anterior, sem protestos. Os manifestantes se organizaram sob o nome de coletivo Contre Exhibit B. Curiosamente, a obra era apresentada como sendo um manifesto contra o racismo e os crimes cometidos contra os africanos. Nas resenhas e relatos jornalísticos dificilmente se encontrou descrições que extravasassem o prospecto da obra. Na pagina oficial do espaço 104 a obra era definida da seguinte forma:

Exhibit B é uma instalação-performance em doze quadros vivos que denuncia os atos cometidos, primeiramente em África, durante o período colonial, e, depois, hoje ainda, na Europa, contra alguns imigrantes africanos. Um capítulo oculto 
de nossa História, cujas construções ideológicas racistas persistem até os dias atuais. $^{3}$

O fato de uma obra que se apresenta como antirracista ser contestada por tantas pessoas com intenções talqualmente contra o racismo, fez com que muitos não compreendessem o que estava acontecendo, a ponto de o pesquisador Eric Fassin afirmar na ocasião que "dois antirracismos se confrontam hoje numa incompreensão mútua" (apud Bataille; Gnammankou, 2015, p. 107). Os diretores dos espaços lançaram comunicados à imprensa em que reiteraram que a obra "denuncia sem ambiguidade toda forma de desumanização, de racismo" (Bellorini; Gonçalvès apud Bataille; Gnammankou, 2015, p. 19).

Entretanto, a própria existência de Contre Exhibit $B$ fornecia indício da possibilidade de ambiguidade na mensagem antirracista da obra. Parece ter havido uma espécie de lacuna no debate francês que suprimiu deliberadamente a crítica. É justamente a existência dessa "ambiguidade" que nos leva a tentar compreender qual ou quais seriam os elementos na obra capazes de despertar tal imbróglio. Quais são os racismos e os antirracismos em cena nesse debate? Exhibit $B$ pode nos servir como objeto para se pensar êxitos e falhas das contra-estratégias ${ }^{4}$ que buscam desconstruir o racismo na arte contemporânea. Tentaremos inicialmente buscar em documentos da montagem da obra - relatos, imagens fotográficas e vídeográficas -, e artigos publicados, as fontes que nos ajudem a nos aproximar, o máximo possível, daquilo que teria sido a experiência dessa performance-instalação.

Exhibit B inicia-se no Waiting Room. No local de espera, o público, geralmente em número máximo de vinte e oito pessoas, é recebido por uma pessoa que o informa sobre o percurso a ser percorrido. $O$ grupo é instruido a esperar e permanecer em silêncio. As vinte e oito pessoas são, então, convidadas a escolher um número, pelo qual serão chamadas desse momento em diante, entrando uma a uma, a cada trinta segundos. Ouve-se Ave Maria, cantado por um coral da cidade de Windhoek. A trilha sonora soma-se em elementos que integram a "apreciação dos quadros vivos". Algum desses quadros contam também com som próprio. No trajeto, lê-se placas com dizeres como: "Os negros foram alimentados," ou que deve-se "Civilizar os indígenas."

Os quadros são acompanhados por placas que explicam as diferentes histórias que serviram como fonte de pesquisa. Ao percorrer as instalações, os atores contratados olham fixamente o público com o objetivo de se criar um olhar inquisidor, gerando mal-estar. A ideia é de inverter o objeto e o sujeito do olhar, sendo essa uma questão importante no discurso do artista. Embora alguns dos quadros envolvam gaiolas ou estruturas fechadas, não há grades que separem o público das instalações, mas postes de cordão, como os utilizados para organização de filas. As instalações são plasticamente bem resolvidas, cujo resultado não passa despercebido da crítica. Ao final do trajeto, o espectador ainda passa pela "Portrait Gallery", uma sala onde a audiência é convidada a refletir sobre a obra. Na Galeria estão dispostos retratos dos

3 Apresentação no website oficial do le 104. Disponível em: < http://www.104.fr/programmation/evenement.html?evenement=358 >. Acesso em: 26 fev. 2015. Todas as citações em língua estrangeira são traduções nossa.

4 Contra-estratégia é o termo utilizado por Stuart Hall sobretudo em seu texto The Spectacle of the 'Other' (1997) onde é empregado para designer notadamente estratégias de resistência. Assim, uma vez contextualizado as intenções contra hegemônicas dessas estratégias, é possível referir-se apenas ao termo estratégia. 
atores junto a seus relatos de contato com o racismo. Há também material para que o público deixe comentários de sua própria experiência com a obra.

A performance surgiu depois do diretor ter contato com o livro de Bernth Lindfords "Africans on Stage: Studies in Ethnological Show Business" (Bloomington: Indiana University Press; Cape Town: David Philip, 1999) que trata dos casos de africanos expostos na Europa e nos Estados Unidos.

Segundo os organizadores da exposição Exhbitions: L'invention du sauvage (2012), os egípcios já expunham "anãos-negros" oriundos das regiões sudanesas; no Império Romano era comum fazer desfilar os "bárbaros" vencidos sob um arco do triunfo como sinal da superioridade do Império; no medievo, pessoas com todo tipo de anomalia física eram expostas, dando origem ao que conhecemos como freak show; e com a expansão europeia na Idade Moderna houve um aumento no interesse pelo insólito advindo de terras distantes.

No século XIX, a exibição do outro se torna o fenômeno que hoje podemos chamar Zoo Humano, ${ }^{5}$ ganhando os contornos que conhecemos através das grandes Exposições Universais (1851-1958), em especial as Exposições Coloniais. Esses eventos ocorreram especialmente na França, nos Estados Unidos, no Reino Unido, na Bélgica, na Alemanha, no Japão, na Austrália e na Itália (Blanchard, et. al., 2012). O tema, embora pouco explorado pela historiografia, é fundamental para compreensão da construção do outro pelo ocidente, pois nesses eventos convergiam o poder colonial, o racismo científico e a superioridade estética, elementos que subsistem no olhar ocidental.

As Exposições Coloniais mostram também que a construção do racismo era algo mais próprio do julgamento estético e do espetáculo que propriamente do científico ${ }^{6}$. Para Arnaut, essa prática do espetáculo da alteridade foi possível através da negação da intersubjetividade que reforçava a desigualdade entre o público e as pessoas expostas. Para o autor, "os zoos humanos podem se definir a mínima como espetáculos interculturais [...] nos quais a amputação da intersubjetividade, no interior da representação, reproduz a subalternidade, histórica ou social, dos atores" (Arnaut, 2012, p. 360). Segundo o historiador Blanchard (et. al, 2012) o fenômeno do zoo humano foi um dos primeiros fenômenos a se tornar mundializado (antes mesmo da música, do esporte ou do cinema), se tornando um modelo genérico.

É difícil imaginar hoje o poder de atração que essas exposições exerciam no público daquele período, mas alguns elementos podem revelar o êxito comercial dessas exposições que marcaram fortemente a cultura visual ocidental. Seguindo Blanchard:

\footnotetext{
5 Do francês zoo humain, o termo que busca designar a prática cultural dos impérios coloniais até cerca do fim da II Guerra Mundial de expor, como ainda se expõe animais em zoológicos, "raças exóticas", ou seja, pessoas da África, América, Ásia e Oceania. Estas eram expostas em forma de espetáculo servindo ao mesmo tempo como propaganda colonial, objeto científico e divertimento do público, sobretudo, branco, europeu e estadunidense. 0 termo foi usado pela primeira vez no livro dos historiadores franceses Nicolas Bancel e Pascal Blanchard intitulado De l'indigène à l'immigré (Gallimard: Paris, 1998), e foi difundido através da exposição no Musée du Quai Branly em Paris Exhibitions, L'invention du sauvage, que ocorreu de 29/11/2011 à 3/06/2012 e expôs variados documentos sobre a prática do zoo humanos. Não obstante, Carl Hagenbeck um dos primeiros a expor humanos com animais chamava suas exposições de "exposições antropozoológicas", já Geoffroy de Saint-Hilaire, que se inspirou em Hagenbeck para fazer em Paris, no Jardin d'acclimatation, o que ele chamava de "exposições etnológicas". (Cf. Blanchard, Pascal. Et al [org.]. Exhinitions: L'invention du sauvage. Actes Sud / Musée du Quai Branly, Paris, 2012.).

6 "O Zoo humano é uma encenação que associa à construção dos grandes impérios coloniais, à construção da ciências do homem e à emergência das teorias racialistas, eugenistas ou segregacionistas, como os mecanismos do capitalismo nascente, e que contribuiu à descoberta desses corpos exóticos por centenas de milhares de visitantes que jamais haviam viajado para esses "países longínquos" e "misteriosos"." (Blanchard, et. al, 2012, p. 21- 22).
} 
[...] três elementos [...] atestam o seu sucesso. Em primeiro lugar, a distribuição de imagens impressas pelos vendedores ambulantes [...] e as vendas impressionantes de cartões postais e outras mídias nos próprios lugares de exposição; mas ainda também o elevado número de artigos na imprensa (nacional e local) consagrado a essas manifestações; e, enfim, a frequência sempre elevada nos vários locais de exposição. Esses indicativos quantitativos apontam para a popularidade desses espetáculos, incluindo as exposições em cidades pequenas. O "selvagem" vende. (Blanchard, et. al, 2012, p. 35):

Como afirmou Arnaut, "os zoos humanos se situam na junção da representação teatral e da subalternidade, e esta conjuga diversidade/alteridade com desigualdade e subjugação" (Arnaut, 2012, p. 344). Milhares de pessoas, cujos corpos objetificados eram privados de identidade e história, foram exploradas dessa forma. Os casos de Saartjie "Sarah" Baartmann, em início do século XIX na Europa, e de Ota Benga, no início do século XX nos Estados Unidos, são os mais conhecidos.

A trágica história de Saartjie é uma das mais lembradas por artistas que buscam denunciar a construção dos estereótipos a partir das históricas práticas culturais de alterização, como o zoo humano. ${ }^{7}$ Saartjie foi retirada da África do Sul onde servia a casa de um fazendeiro para ser exposta em espetáculos circenses na Europa. Em Londres e Paris ela se tornou objeto de divertimento e de pesquisas científicas. As más condições de vida fizeram com que a saúde de Saartjie se deteriorasse rapidamente, vindo a falecer com vinte e seis anos. Saartjie continuou a ser exibida mesmo após sua morte: seus restos mortais e o molde de seu corpo podiam ser vistos no Museu do Homem em Paris até meados da década de 1970. Saartjie é representada em um dos tableaux vivents de Bailey intitulado "the missing link or Sarah".

O quadro referente à Saartjie, também chamada Sarah, não parece se remeter à forma como ela era exposta em vida, visto que a atriz não carrega o vestuário que era dado à Saartjie, com a finalidade de deixa-la mais "autenticamente primitiva". O quadro nos lembra mais ao molde que foi feito do seu corpo e exposto no Musée de l'homme, em Paris, com a diferença que em Exhibit $B$ a atriz, além de calçar sapatos, carrega consigo alguns acessórios discretos. Outros quadros que constituem a instalação são Origins of the species, Still life, The age of enlightenment, Civilizing the natives, Dr. fisher's cabinet of curiosities e A place in the sun, que tratam de diferentes formas da violência no colonialismo.

O termo Exhibit não significa somente uma exibição ou uma mostra, Exhibit pode se tratar tanto de um objeto exposto em um museu como, em um contexto jurídico, pode significar uma evidência demonstrativa. Trata-se de uma evidência física, ao exemplo da fotografia, que serve como prova em um processo criminal ou em um julgamento civil. Nesse processo, as provas são comumente numeradas com letras a fim de diferenciá-las umas das outras. É este o sentido empregado por Bailey em sua The Exhibit Series (2010-2013).

Bailey tem a intenção de trazer provas das violências coloniais. O quadro A place

7 Alguns exemplos são: Lyle Ashton Harris e Renée Cox "Venus hottentot 2000" (fotografia 1995); Renee Cox, Hot En Tot (fotografia, 1994); o filme de Abdellatif Kechiche, Vénus noire (2010); o quadrinho homônimo de Abdellatif Kechiche e Renaud Pennelle, Vénus noire também de 2010. 
in the sun ${ }^{8}$ nos apresenta um quarto tomado pela tonalidade amarela onde vemos fotografias e artigos ligados ao período colonial, como cabeças de antílopes. A atriz está acorrentada à cama a partir de seu pescoço, de costas para o público, observando-o pelo espelho. $O$ quadro sugere um cenário de violência sexual cometida pelo oficial das forças coloniais no qual a ameaça do estupro pode se realizar a qualquer momento, de novo. O título, um lugar ao sol, parece lidar ironicamente com as relações sexuais forçadas, que ao mesmo tempo podia ser uma das únicas formas de garantir a sobrevivência. Botas, roupas e objetos do oficial se encontram jogados pelo quadro, sugerindo a presença do "colonizador", ausente nos demais quadros.

Sabemos, principalmente através dos trabalhos oriundos do estudos pós-coloniais, como o de Said, Mudimbe e Hall, que a imagem do outro foi construída em oposição à imagem do ocidente, e essa relação não pode estar ausente caso o objetivo seja de desconstruir essa contraposição. Albert Memmi, na década de 1950 já havia demonstrado que o fato colonial (fait colonial) passa pela condição objetiva que se impõe às duas partes da colonização, colonizador e colonizado, no qual as definições do racismo se estabelecem na relação de dominação de um grupo sobre o outro. Assim, "a noção de privilégio é o coração da relação colonial" (Memmi, 2012, p. 15) e se constitui como a herança mais nefasta perpetuada na contemporaneidade. Esta relação, no entanto, parece estar ausente dos quadros que tratam justamente de colonização e do racismo.

Se esses fossem os únicos quadros, poderíamos nos questionar sobre a necessidade de conscientização hoje contra essas expressões de violência colonial, entretanto, Exhibit $B$ tem o mérito de relacioná-la com a contemporaneidade através dos quadros Found object \#1, \#2 e \#3; Separate development, Travail et progress, Survival of the fittest e Wider, Still and Wider. Estes quadros falam sobre o problema contemporâneo das políticas migratórias europeias permeadas pelo racismo e abordam questões sobre busca de asilo e exploração do trabalho. Contudo, os personagens continuam despersonalizados, sem nome e sem história, pois estão dispostos como objetos, e se não fosse o olhar projetado pelos atores estariam inanimados. Assim, as imagens que o artista apresenta não trazem avanços em relação ao já conhecido repertório de imagens do regime de representação racializado. Avanços esses que esperamos de uma obra antirracista.

Stuart Hall em The West and the Rest (1995) mostra como a expansão europeia possibilitou a criação da imagem homogênea da Europa como local de civilização e criou igualmente uma imagem homogênea do "resto" dominado pela condição selvagem. É nesse período que o arquivo sobre o "resto" se desenvolveu e, segundo Hall, foi alimentado principalmente pelo conhecimento clássico; fontes bíblicas e religiosas; mitologia e os relatos dos viajantes. Segundo o autor, "[...] esses diferentes discursos, com variado estatuto de 'evidência', forneceram o enquadramento cultu-

\footnotetext{
8 Na versão do quadro exposto em Exhibit A, A place in the sun era identificado como um quarto de um oficial da força colonial alemã de Windhoek, em 1906; a atriz portava um número de série em sua lombar. A imagem teria sido inspirada por uma fotografia mantida pelo Braunschweigisches Landesmuseum, museu de história e arqueologia localizado na Alemanha, sendo uma clara referência aos crimes cometidos no contexto considerado como o primeiro genocídio do século $X X$, que foi o genocídio dos hererós e dos namaquas, que ocorreu no Sudoeste Africano Alemão. O número em série refere-se ao primeiro emprego em campos de concentração pelos alemães, que já o utilizaram no genocídio dos hererós e namaquas anteriormente à Shoah. Já na versão para Exhibit $B$, a mulher está sem o número de série, e a legenda identifica como um quarto de oficial francês. Em ambas as versões, perto à mulher, amarrada como um animal, vê-se um rifle e outros elementos de coerção e violência.
} 
ral através do qual as pessoas e as coisas [...] foram vistas, descritas e representadas" (Hall, 1995, p. 299).

Esse arcabouço serviu de base para a racialização do "outro", especialmente das pessoas negras, cujo arquivo foi construído em três importantes momentos. Segundo Hall (1997), essa construção começa no encontro dos comerciantes europeus com os reinos africanos, que forneceram pessoas escravizadas por três séculos, passa pela colonização e divisão da África e continua na contemporaneidade através da migração dos países, outrora chamados "de terceiro mundo", rumo ao norte, Europa e Estados Unidos, a partir da Segunda Guerra Mundial. Nesse sentido, um importante elemento na construção desse arquivo sobre a racialização humana é a exibição do outro para divertimento ou para evidência científica da inferioridade racial que produziu muitas imagens e discursos entre fins do século XVIII até meados do século XX e ainda exercem forte influência na linguagem e na representação ocidental, como na manutenção de estereótipos ${ }^{9}$.

Durante os protestos de Paris contra Exhibit B, Brett Bailey creditou o imbróglio a um grande mal-entendido "por parte das pessoas que não viram a instalação" (Pereira, 2015). Ele afirmou que a obra é destinada prioritariamente ao público branco (Uleski, 2014). Na França, diferentemente de Londres, o artista e a obra foram amplamente defendidos pela grande maioria das instituições, personalidades e organismos concernidos, como la Ligue des droits de l'Homme (liga dos direitos do homem), o Mrap (Movimento contra o racismo e pela amizade entre os povos), a Licra (Liga internacional contra o racismo e contra o antisemitismo), l'Observatoire de la liberté de création (Observatória da liberdade de criação); o Syndeac (Sindicato profissional das artes performativas) e especialistas como Lilian Thuram, ex-futebolista e criador da Fundação que leva seu nome (atua na educação contra o racismo); Pascal Blanchard, historiador especializado em Império colonial francês e na história da imigração; e Jean-Loup Amselle, antropólogo ligado à EHESS e dedicado a temas africanos. A defesa foi tomada também pelo Ministério da Cultura e pela Prefeitura de Paris que condenou qualquer tentativa de censura.

Essa reação de ampla defesa ancorou-se em dois argumentos principais que parece ter impedido o diálogo com seus críticos. Primeiro: a desaprovação vinha de quem não vira a obra pessoalmente; segundo: o objetivo do grupo seria o de censurar e, portanto, impedir o exercício da liberdade de expressão e criação artística. Isso acabou possibilitando um retrato do coletivo como autoritário censor e ignorante sobre arte. Como afirma a militante Sabrina, ocorreu uma "diabolização" do movimento, o que dificultou a recepção da crítica pela mídia (vídeo L'exposition scandaleuse) ${ }^{10}$. Contre Exhibit $B$ foi acusado de ser violento, não possibilitar diálogo (pois pediam na petição a "desprogramação" da obra) e de não ter capacidade para compreender o antirracismo sem ambiguidade da obra, assim como, de não entenderem

\footnotetext{
9 Partindo ainda da compreensão de Hall, estereotipar designa uma prática representacional que simplifica, reduz, exagera, essencializa, naturaliza e cria oposições binárias. Ou seja, trata-se de uma prática em que se escolhe uma informação apenas sobre algo ou alguém, essa informação é ampliada, como em uma caricatura e, depois, passa a ser entendida como o âmago e a natureza primeira e única desse algo ou alguém. Nesse sentido, um dos mais fortes estereótipos baseados na racialização do ser humano trata da pessoa negra, que foi desde o princípio identificada com a natureza, simbolizando o primitivo no contraste com o mundo civilizado branco.

10 META TV. L'exposition scandaleuse - Rassemblement Anti-Exhibit B. Disponível em: <http://www.dailymotion.com/video/x2c1ypq_l-exposition-scandaleuse -rassemblement-anti-exhibit-b-meta-tv_tv?start=335> Acesso em: 10 mar. 2015.
} 
o direito fundamental de liberdade de expressão. Ironicamente, a imagem do primitivo não-civilizado parece ter ecooado no grupo.

Dentre os integrantes do Contre Exhibit $B$, houve aqueles que assistiram à performance, embora a maioria achasse desnecessário ver a obra pessoalmente, já que identificou por fotografias e relatos uma representação racializada. $O$ ator Guillaume Mivekannin, que trabalhou em Exhibit $B$, por exemplo, conta da reação de um espectador: "Um dia, um homem chegou, ou melhor, aterrissou. Ele fulminava, o olhar de desaprovação. Ao fim do percurso, acabou por gritar algo como "dignidade, respeito!," antes de ser empurrado para fora por um policial à paisana" (Fabre, 2014). Dominique Sopo, presidente da associação SOS racisme, defende que as boas intenções e as reflexões do artista já são suficientes para fazer com que a demanda por interdição seja, em suas palavras, contra-produtiva (Sopo, 2014). Revelando que a defesa da obra tampouco se apoiou na "apreciação da obra", confiando na intenção expressa e no histórico do artista.

Sobre a questão da censura e da liberdade de expressão, trata-se realmente de matéria importante e de direitos a serem protegidos. Para compreender realmente a existência de intenções autoritárias como a censura, precisaríamos identificar como ocorreu a possibilidade de diálogo, o que variou a cada cidade palco das manifestações. Porém, algo sintomático é que no debate suscitado pela performance instaurou-se uma oposição inflexível entre racista/antirracista, censura/liberdade, o que impediu o diálogo. Seria necessário talvez um debate jurídico sobre a possibilidade de estar havendo um choque entre direitos fundamentais, entre liberdade de expressão e dignidade humana. Mas pretendo não desviar de meu interesse em identificar racismos ou antirracismos nas estratégias representacionais de Exhibit $B$.

Muitos confundiram as críticas do coletivo à uma crítica geral sobre a incapacidade de representação de um passado traumático. Esse debate foi frequente no período pós-segunda guerra, momento em que se questionava se os horrores do Holocausto poderiam, ou ainda, se deveriam, ser representados. Foi desta forma que interpretou, por exemplo, Pascal Blanchad, tomando defesa da obra. ${ }^{11}$ No entanto, o coletivo foi pontual em sua crítica relativa ao modo de representação, e não à representação por si só. Segundo Uleski (2014), os principais problemas identificados pelo grupo são:

- Instrumentalização do corpo, um corpo negro e mudo, que reforça estereótipos raciais.

- Ausência do opressor

- Ausência da representação de resistência ou de luta do "movimento negro"

- O negro é eternamente apresentado na posição de vítima

- Nenhuma menção específica do racismo contra o negro, a saber a negrofobia.

\footnotetext{
11 "C'est comme s'il y avait une sorte d'interdit à montrer. Mais c'est exactement la même chose que ceux qui, dans les années 60, 70, refusaient qu'on parle de la Shoah. Il y avait une volonté de cacher, y compris de la part de ceux qui l'avaient vécue. Ils ne voulaient ni revoir, ni voir. Quand vous avez vécu l'horreur, vous n'avez pas envie de retraverser ces images-là. Si cela se comprend en termes psychanalytiques, en termes de prise de conscience pour l'occident de ce qu'a été la Shoah, le colonialisme ou les zoos humains, il y a un moment où il faut être mis face aux faits, aux crimes, à la difficulté de les voir. Que les zoos humains soient durs à voir prouve leur violence". In : Pascal Blaadnchard: Exhibit B force à voir le racisme les yeux dans les yeux : Entrevistado por Caroline Châtelet. In: Regards. fr , 1 dez. 2014. Disponivel em: http://www.regards.fr/web/article/pascal-blanchard-exhibit-b-force-a>. Acesso em: 01 mar. 2016.
} 
A obra de Brett Bailey nos remete diretamente à outra performance inspirada nos zoos humanos criada pelos artistas estadunidenses Coco Fusco e Guillermo Gómez-Peña em 1992 e intitulada The Year of the White Bear and Two Undiscovered Amerindians Visit the West (O ano do Urso Branco e dois não-descobertos ameríndios visitam o ocidente).

Nessa performance, os artistas se apresentaram como dois indígenas recém contactados vindos de um "povo isolado" da Ilha fictícia chamada Guatianau, no golfo do México. Mais conhecida pelo título de The Couple in the Cage ${ }^{12}$, a performance tinha o objetivo de criar um comentário satírico do passado colonial e suas exposições humanas. Vestidos de forma estranha tanto para um euro-estadunidense quanto para um indivíduo de sociedades ameríndias, Fusco e Gómez-Peña deixam claro, com vestimentas e objetos bizarros, a paródia colonial sobre a construção do "outro". Fusco usa, por exemplo, saia de palha com o tênis converse, rosto pintado, boné e biquíni com estampa animal. Gómez-Peña, por sua vez, usa uma máscara tigrada, semelhante às de couro ou látex vendidas em sex shops para jogos sexuais como bondage, além de munhequeiras com spikes e rebites, artigo bastante associado à cultura gay leather, aos adeptos do sadomasoquismo, e a alguns grupos ligados ao heavy metal. O figurino de Gómez-Peña se assemelha a uma fantasia comprada em lojas de artigos para carnaval ou halloween. Como se vê, a intenção não era de convencer as pessoas da veracidade dos ameríndios, mas de criar uma caricatura grotesca.

Para surpresa dos artistas, parte do público acreditou se tratar realmente da exposição de duas pessoas de um povo até então desconhecido. Como relata Fusco, na Espanha mais da metade do público pensou se tratar de "autênticos" ameríndios, embora houvesse aqueles que iam para, justamente, ver a reação dessas pessoas que "levaram a performance à sério". Segundo o artista Gómez-Peña houve inclusive reações de solidariedade como pessoas oferecendo presentes ou escrevendo bilhetes de simpatia. Algumas dessas reações foram de revolta à desumanização que era vítima o casal exposto em uma jaula. Outras foram de extrema violência, a exemplo de um senhor que fazia sons de macaco, de um grupo de neonazistas que tentaram chacoalhar a jaula ou de um grupo de adolescentes que tentaram queimar o artista com pontas de cigarros (Johnson, 2013).

Fusco conta ainda que as reações das pessoas que chama de nativas norte-americanas e latinas ${ }^{13}$ foram diferentes das reações do público branco. Enquanto os primeiros tendiam a identificar os erros na hibridação sugerida pelos elementos contidos na gaiola, os brancos identificavam nesse mesmo conteúdo um sinal de aculturação e de falta de originalidade. A questão da autenticidade acabou permeando a recepção da obra (Johnson, 2013).

Se "desmontarmos" os elementos dessa performance, referência na historiografia da arte contemporânea, principalmente das artes visuais, perceberemos que ela é composta de elementos inversos das estratégias utilizadas por Brett Bailey. Na obra de 1992, os artistas desempenham eles próprios os autênticos "Guatinauis" e apesar de ambos serem considerados "latinos" essa informação não foi fulcral para a obra

12 É o título do registro: The Couple in the Cage: Guatianaui Odyssey . 31:00 min, B\&W and color, sound, 1993. Dirigido por Coco Fusco e Paula Heredia.

13 Termos empregados nos Estados Unidos para designar, respectivamente, os povos autóctones do território estadunidense e as pessoas cuja origem remonta à América Latina. 
uma vez que estavam completamente fantasiados. Alguns entre o público se questionavam sobre a "branquitude" dos dois ameríndios expostos (percebidos por alguns como demasiado brancos para serem indígenas). Atrizes encenavam as mulheres que anunciavam e promoviam a ação como se fossem os antigos proprietários e agentes de espetáculos. Elas vestiam tailleur e faziam a mediação com o público, inclusive colhendo, a partir de observação, relatos sobre o comportamento do público.

O fato de Brett Bailey ser branco foi seguidamente lembrando e levou muitos a pensar que o problema residia na reprovação dos militantes em relação a um artista branco falar sobre o racismo. Foi esta a interpretação, por exemplo, de Pascal Blanchard. Segundo o historiador, Exhibit $B$ passou a ser objeto de protesto por influência de uma "consciência comunitária" importada dos Estados Unidos que reserva determinados combates apenas àqueles diretamente a eles implicados, por exemplo, aos judeus a luta antissemita, aos negros a luta contra o racismo anti-negro, aos homossexuais a luta anti-homofobia (Blanchard, 2014). A brancura de Brett Bailey pesa na análise de toda a conjuntura, mas não é fator predominante ou isolado, uma vez que essa informação é insuficiente para gerar oposição. Artistas visuais e brancos como a brasileira Adriana Varejão e o português Vasco Araújo tratam incessantemente do passado colonial de ambos os países, e por isso, não se furtam de tratar também do racismo, realidade atrelada ao fato colonial, sem que sejam impedidos de o fazer por serem brancos, como mostram obras das séries Polvo (2013) e Filho Bastardo (1992), de Varejão, ou Botânica (2012-2014) e Debret (2013), de Araújo, ou mesmo a obra do sul-africano, e também branco, William Kentridge, que trata sobretudo da desigualdade social, abordando por vezes, o racismo.

A luta antirracista, acaba tendo de operar com a mesma categoria que combate, a saber: a raça, e por isso deve realmente se policiar para não incorrer em essencialismos no lugar de desconstrui-los. Isso é um perigo constante. Entretanto, o que parece permear Exhibit $B$ é uma problemática mais ampla que envolve seu processo e sua execução.

Brett Bailey realiza audição em cada cidade que hospeda a obra. Com o grupo Third World Bun Fight, Bailey leva sua equipe, pois para essas obras exige-se investimento e treino dos artistas. Já para uma performance como Exhibit $B$, o ator deve apenas cumprir requisitos físicos: se parecer ao personagem e suportar ficar determinado período de pé. O diretor acaba por repetir quase como uma paródia a relação entre senhor branco e escravo negro, e a divisão capitalista do trabalho; divisão que consiste na separação entre trabalho intelectual e trabalho manual na qual o trabalho intelectual é desempenhado por poucos que tem acesso a formação e cuja recompensa é incomparavelmente superior ao do trabalhador manual que desempenha tarefa repetitiva, de pouco treino e baixo pagamento, pois sua mão-de-obra pode ser facilmente substituída.

Fusco e Gómez-Peña operam uma inversão do olhar. São eles que, apesar de estarem dentro da jaula, estão conscientes do que está ocorrendo e observam o comportamento do público. As pessoas podem interagir e se tornarem interlocutoras. Haviam "trocas" programadas. Era possível pagar cinquenta centavos de dólares para ver a "fêmea" dançar ou ouvir o "macho" contar histórias em uma língua fictícia "falada por seu povo". Pagava-se apenas cinco dólares para ver as genitálias masculi- 
nas. As pessoas também podiam livremente comunicar-se com os "guatinauis" e com as "promotoras". Na Performance de Bailey, o público deve percorrer o trajeto em silêncio e depois de conhecer as histórias de crueldade poderia, em espaço reservado para a atividade, deixar um relato sobre sua experiência ou sobre seu aprendizado. A "inversão" do olhar criada por Brett Bailey parece mais dedicada a um lançamento da culpa, dando um aspecto de via-sacra. Na Igreja Católica a via-sacra consiste no exercício no qual os fiéis devem percorrer mentalmente a caminhada de Jesus que parte do pretório de Pilatos carregando a cruz até o monte Calvário onde é crucificado. Na via-sacra de Bailey, o público também deve refletir sobre uma gama de crueldade infringidas contra as pessoas negras e enquanto os atores direcionam seus olhares inquisidores, o público deve permanecer em silêncio nesse percurso meditativo sobre a culpa dos horrores cometidos. Isso confirma a afirmação do artista de que a obra seria destinada a um público branco.

Em texto sobre a espetacularização do "Outro" (1997) Stuart Hall propõe analisar o arquivo das representações racializadas, principalmente em seus agenciamentos contemporâneos, e investiga também estratégias que buscam desconstruir este regime racializado. $O$ autor se centra em imagens de objetos, passa pelo cinema e a publicidade até a arte visual contemporânea, para identificar contra-estratégias, ou seja, estratégias visuais contra-hegemônicas que se constituem como visualidades antirracistas. As primeiras contra-estratégias, ou poderíamos chamar de contra-estratégias históricas, atuaram em um contexto em que as identidades eram entendidas de forma binárias. Essas primeiras estratégias se deram nas reapropriações e ressignificações de sentidos dados ou na criação de imagens positivas para combater a hegemonia das imagens estereotipadas. Exemplos dessas ressignificações em contexto de compreensão binária são os movimentos négritude na década de 1940 e Black is beautiful na década de 1960.

A abordagem que para Hall parece mais interessante opera fora das noções binárias, e para explicá-la, o autor se utiliza sobretudo de exemplos da arte contemporânea. Para desconstruir noções essencializadas, essa abordagem parte de uma diferença construída na repetição, differance ${ }^{14}$, ausente de dualidades e que questionam noções de autenticidade, já que a fonte do significado ou um fim do diferimento não são identificáveis. Nessa contra-estratégia, o objetivo é de desmontar a imagem minando a própria operação da representação a partir do interior de seu funcionamento. O autor cita o exemplo do artista Isaac Julien para mostrar como a desconstrução do regime racializado exige "adentrar" a construção do estereótipo, ir onde o sentido está encerrado, desmontar e expor esses elementos revelando os momentos em que foram reduzidos e naturalizados.

Nesse sentido, vemos na performance de Coco Fusco e Guillermo Gómez-Peña uma abordagem bastante aproximada do que seria essa terceira estratégia, uma vez que parodiando os elementos que construíram a imagem do outro, no caso o ameríndio, ela expõe as articulações que constroem diferenças, que apesar de móveis, foram fixadas historicamente na imagem do outro. Os artistas operam essa desconstrução expondo como "o fetiche sobre a autenticidade está conectado com uma

14 Termo derridarano de difícil tradução, poderíamos traduzí-los por diferância ou diferência. 
ideia que a pessoa não-ocidental não tem um senso de reflexividade sobre ela própria" (Fusco apud Johnson, 2013). Ou ainda, de que operam numa temporalidade e numa narrativa diversa. Nas palavras de Gómez-Peña, "a questão principal é que não querem que nós façamos parte do mesmo presente ou do mesmo tempo. Eles querem que operemos fora da história". (Gómez-Peña apud Johnson, 2013).

Pensando a partir de Stuart Hall e de The Year of the White Bear ...., vemos que Exibit B apresenta, sim, ambiguidades. Exibit B não tem por objetivos oferecer imagens positivas ou uma ressignificação dos estereótipos, como ocorre nas contra-estratégias históricas, tal como delineada por Hall, mas tampouco se trata de colocar a representação racializada sob escrutínio. Ao contrário, por vezes podemos encontrar em Exibit B o "outro" autêntico, como explicou Gómez-Peña, inocente e incapaz de auto-reflexividade.

Okwui Enwezor (2002) realizou uma crítica sobre o uso da imagem do corpo negro na expressão cultural e política da nova África do Sul pós-Apartheid. Através de exemplos da produção artística sul-africana - como alguns trabalhos de Penny Siopis, Santu Mofokeng e Candice Breitz -, Enwezor demonstrou como ocorrem nas imagens desses artistas uma higienização das histórias de violência e dominação, uma supressão da historicidade das pessoas representadas e uma obliteração das individualidades dos corpos representados, reiterando uma representação de estereótipos própria do regime de visualidade racializado. Segundo Enwezor:

\begin{abstract}
Apesar da sinceridade com que artistas vem ousadamente mantendo uma relação com o corpo negro em seus trabalhos, existe uma sobre-determinação que acompanha seus gestos. Eles parecem negligenciar o fato de que a forma negra é tanto um grotesco portador de experiências traumáticas quanto é um receptáculo abjeto da raça como ponto de diferenciação. Mais do que nos alertar para a forma como o estereótipo fixa seus objetos de desejo nesse enquadramento da realidade, como já dado, o trabalho desses artistas exacerba o estereótipo por repeti-lo, talvez inconscientemente, como se tivesse sido sempre factual. O problema com esse tipo de trabalho é que ele é tão fixado no corpo que se nega a dar conta da divisão psíquica mais crucial que posiciona os corpos negro e branco em polaridades de mérito e valor. Ao tentar fundi-los, ainda que forçadamente, e tendo como licença o fato de sua branquitude, eles repetem aquele ato de sucedâneo ${ }^{15}$, que enfatiza a mudez e o silêncio do sujeito, enquanto seguem glorificando suas próprias posições como vozes da realidade, como as vozes totais da verdade (Enwezor, 2002, p. 387).
\end{abstract}

Em contrapartida, segundo historiador e curador, os artistas negros na África do Sul utilizam menos a imagem do corpo e quando a utilizam, a usam de forma a proporcionar uma reflexão sobre os desejos e os significados de ser negro sobre a dominação colonial, "restaurando" histórias e identidades das pessoas que figuram nas imagens trabalhadas, como no projeto Black Photo Album/Look at Me: I89Q-1950S de Santu Mofokeng.

No Brasil, as manifestações parecem não ter tido a necessidade de ganhar as

150 termo originalmente usado pelo autor é surrogacy, termo que sugere mais à "maternidade por substituição", o que conhecemos por "barriga de aluguel". 0 autor se refere ao que chamamos de "paternalismo" quando relações de poder são disfarçadas através de medidas de proteção ou de pretensa "defesa" dos que se encontram em posição de desigualdade. 
ruas. A petição brasileira arrecadou apenas 4.323 assinaturas ${ }^{16}$, número bastante reduzido se comparado às petições francesa (20.750) e inglesa (22.982). Contudo, o desenrolar do debate no Brasil tomou um rumo bastante diferente.

O que talvez nos ajude a compreender essa diferença foi a antecedência da polêmica ligada à encenação da peça de teatro $A$ mulher do trem da companhia Os Fofos Encenam. A montagem foi centro de um debate sobre representação racista em maio de 2015, portanto, antes do país receber os quadros-vivos de Brett Bailey, como estava programado. A mulher do trem é uma peça escrita pelos franceses Maurice Hennequin e George Mitchell em meados do século XIX e foi encenada pela companhia pela primeira vez em 2003, que a reencenariam no dia 12 de maio de 2015, em São Paulo, na programação do Terça Tem Teatro, promovido pelo Itaú Cultural. A peça utiliza-se do recurso circense de máscaras e um dos personagens, a empregada doméstica, utiliza uma máscara preta, formalmente idêntica ao recurso conhecido como blackface ${ }^{17}$. A partir das fotografias promocionais da peça, Stephanie Ribeiro, estudante e integrante do blogueiras negras denunciou a prática do blackface e do racismo inerente à prática representacional mobilizando um grande número de jovens contra a peça. Em resposta às manifestações públicas, o Itaú Cultural propôs um debate no horário reservado à montagem da peça. O debate "Arte e Sociedade: a Representação do Negro" aconteceu no dia 12 de maio de 2015, na sede do Itaú Cultural, em São Paulo/SP, onde reuniu militantes do movimento negro, artistas e intelectuais ${ }^{18}$ em torno da questão, constituindo desde o início um marco do debate antirracista nas artes brasileiras.

No debate não houve defesa da prática do blackface. A defesa da peça tentou mostrar que a pesquisa sobre máscaras realizadas para o espetáculo residia em uma longa tradição ocidental. Portanto, se inspiravam na linguagem da Commedia Dell'arte europeia e não propriamente do blackface estadunidense. Apesar de alguns acusarem a possibilidade de estar havendo censura, Fernando Neves, diretor de Os Fofos Encenam, mostrou-se sensibilizado com as demandas iniciadas pela denúncia de Ribeiro, entendendo que se a recepção das máscaras estava sendo diferente do que ele havia incialmente projetado, o artifício deveria ser alterado, pois a recepção da obra estava sendo prejudicada ${ }^{19}$.

Intenção do artista e recepção do público são duas instâncias importantes nes-

\footnotetext{
16 Petição brasileira contra Exhibit B:

<https://secure.avaaz.org/po/petition/MITSP_ESPETACULO_EXHIBITB_Cancelamento_do_espetaculo_exhibitb_Zoologico_humano/?nBrwyjb>. Acesso em: 10 de fev. 2016.

17 Este recurso é mais ligado à tradição estadunidense de teatro, a ponto de não termos um equivalente em português do termo. Nos E.U.A o recurso foi popular no século XIX em atrações como os minstrel shows e servia principalmente para criar um retrato risível da pessoa negra. No Brasil ele representou sobretudo a invisibilidade dos artistas negros, como mostra sua utilização n'A Cabana do Pai Tomás. Esta novela da Rede Globo transmitida entre 1969 e 1970 foi a primeira a contar com o personagem protagonista negro, que no entanto, foi interpretado pelo ator branco Sérgio Cardoso pintado de preto, ele era mascarado de preto, blackfaced, para atuar como o Pai Tomás.

18 O debate foi mediado por Eugênio Lima, DJ e ator, membro fundador do coletivo Frente 3 de Fevereiro e do Núcleo Bartolomeu de Depoimentos. Além da estudante de arquitetura e ativista Stephanie Ribeiro e de Fernando Neves, pesquisador, ator e um dos diretores da companhia Os Fofos Encenam, o debate contou com a participação dos convidados: Roberta Estrela D'Alva, atriz do Núcleo Bartolomeu de Depoimentos e também integrante do Frente 3 de Fevereiro; Dennis Oliveira, professor da Escola de Comunicações e Artes da Universidade de São Paulo (ECA/USP) e coordenador do coletivo Quilombação; Mario Bolognese, professor de teatro da Universidade Estadual Paulista (Unesp) e pesquisador do circo brasileiro e Aimar Labaki, dramaturgo, roteirista, diretor, tradutor e ensaísta e Salloma Salomão, educador, músico e representante da Cia. do Teatro e da intervenção urbana Os Crespos.

19 Segundo material do jornal Folha de São Paulo, a peça voltou a ser encenado e passou por revisão conceitual não apenas da máscara preta, mas de todo o conjunto. A atriz do grupo Kátia Daher, afirmou ao jornal que o grupo não se sentia censurado e que entendiam os motivos das reivindicações; apesar de muitos considerarem o ocorrido como censura prévia ou autocensura (Cf. Fioratti, Gustavo. Pela "A Mulher do Trem" abre mão de "blackface" após críticas de racismo. Folha de São Paulo, São Paulo, 25 set. 2915).
} 
se debate. Brett Bailey, diferentemente de Fernando Neves, privilegiou sua intenção ante à recepção por uma parcela do público. No conceito de "obra aberta" que Umberto Eco postulou sobre a arte contemporânea ainda em 1962, o intelectual desenvolveu a noção de que toda obra é aberta, ou seja, não comporta apenas uma interpretação. Embora Exhibit $B$ pareça inicialmente carregar apenas um sentido: a violência colonial, acabou sendo portadora de duas interpretações completamente opostas. Para uns é racista, para outros é antirracista. Para os que desconsideram que a obra possa ser considerada racista a ideia de racismo pressuposta é a do racismo como preconceito e como prática discriminatória, o que não se encontra na obra Brett Bailey. Já para aqueles que vêm a obra como racista se referem ao racismo que persiste no regime de visualidade e na estrutura social que, embora mais sinuoso, é o fenômeno que alimenta e perpetua expressões mais claras e violentas, e é observável em Exhibit $B$.

Este evento é significativo de mudanças singulares na luta antirracista que vem cada vez mais se preocupando com a desconstrução do regime de representação racializado. Isso ajuda a explicar a mudança em relação à recepção de Exhibit $B$ de 2010 para 2014. Um exemplo desse processo, se deu na última edição da entrega do prêmio Oscar, em 2016. Esta edição foi cercada pela polêmica da ameaça de boicote liderado pela atriz Jada Pinkett Smith e pelo cineasta Spike Lee motivados pela falta de indicações de profissionais negros. As indicações ao Oscar são feitas através de votação dos membros da Academia, que é composta por profissionais ativos ou aposentados do setor cinematográfico, majoritariamente homens brancos acima dos cinquenta anos. A chamada para o boicote tomou as redes sociais na internet com a hashtag \#OscarSoWhite (Oscar tão branco) e a própria presidente da Academia Cheryl Boone Isaacs, afirmou estar frustrada com a falta de diversidade, acreditando ser necessário realizar mudanças na imagem dos membros da Academia, sem especificar as futuras ações.

O apresentador da cerimônia, o comediante Chris Rock, tratou do tema desde o monólogo de abertura. O excerto que nos interessa é o momento em que Rock pergunta, retoricamente, sobre o motivo da polêmica acontecer justamente no $88^{a}$ edição da premiação, se edições anteriores foram igualmente ou ainda mais excludentes, ao que responde "[...] nós tínhamos coisas reais para protestar [...]" (Rock, 2016 $)^{20}$. Mais adiante, o apresentador mostra que, a seu ver, não se trata de os protestos contra a falta de representatividade nas indicações serem irreais ou desimportantes, mas que se trata de uma outra forma de racismo a ser combatido:

É um tipo diferente de racista. Agora, eu lembro de uma noite em que eu estava em uma festa beneficente para [a campanha do] presidente Obama, muitos de vocês estavam lá. E você sabe, estava eu e toda Hollywood. [...] Então, em algum momento você consegue tirar uma foto com o presidente. E eles estão preparando para fotografar. Você tem um pequeno momento com o presidente. E eu tipo

20 Original completo: "Now the thing is, why are we protesting ... the big question, Why this Oscars, why this Oscars? It's the 88th Academy Awards. The 88th Academy Awards. Which means this whole no black nominees thing has happened at least 71 other times. Okay, you gotta figure that it happened in the ' 50 s, in the '60s. You know, in the '60s, one of those years Sidney [Poitier] didn't put out a movie. I'm sure there were no black nominees those years. Say '62, '63. And black people did not protest. Why? Because we had real things to protest at the time. You know. We had real things to protest. We were too busy being raped and lynched to care about who won for best cinematographer. When you're grandmother's swinging from a tree, it's really hard to care about best documentary foreign short. What happened this year? What happened? People went mad. [...]." (Rock, 2016). 
- 'Senhor Presidente, você vê todos esses escritores e produtores, atores, eles não contratam pessoas negras. E elas são as pessoas brancas mais legais do planeta, elas são liberais ${ }^{21}{ }^{222}$ (Rock, 2016).

O racismo hoje passa a ser escrutinado em todas as formas de expressão, não se limitando às expressões de extrema violência como a discriminação, a humilhação ou mesmo o aniquilamento da pessoa racializada, que infelizmente ainda ocorrem com frequência espantosa. Em que pese a necessária continuidade do combate contra o racismo enquanto preconceito e enquanto prática discriminatória, principalmente hoje em que percebe-se um acirramento nas manifestações de sentimentos racistas e nacionalistas, há também o racismo perpetrado pela representação racializada. Brett Bailey defende sua intenção antirracista para a construção de Exhibit $B$. Entretanto, Exhibit B ofereceu a "evidência" de como, diferentemente do que projetara o artista, ainda operamos fortemente em um regime de visualidade racializada e temos dificuldades em repensá-las.

Há dois registros fotográficos das manifestações contra Ehxibit $B$, uma em Paris e outra em Londres, que trazem mensagem significativas sobre o antirracismo contemporâneo. Em seus cartazes liam-se dizeres como "descolonizemos os imaginários" (Décolonisons les imaginaires, Paris) e "uma exposição do privilégio branco" (An exibition of white privilege, Londres). As manifestações contra a Exhibit $B$ foram manifestações contra o regime de visualidade racializado, dando prosseguimento, por sua vez, à busca por uma descolonização do imaginário e de questionamentos do privilégio branco. São processos irmanados, pois a colonização do imaginário tratou justamente de criar um imaginário branco. Esse evento nos revela um momento de busca por novas formas de representação como parte de uma demanda por novas histórias e novas imagens.

\section{Referências}

ARNAUT, Karel. Les zoos humains, (mauvais) spectacles interculturels. In : BLANCHARD, Pascal. Et al [org]. Exhinitions: L'invention du sauvage Actes Sud / Musée du Quai Branly, Paris, 2012

BATAILLE, Jean-Marie; GNAMMANKOU, Dieudonné. Contre Exhibit B. Paris : Dagan, 2015.

BLANCHARD, Pascal. Et al [org]. Exhinitions: L'invention du sauvage Actes Sud / Musée du Quai Branly, Paris, 2012.

\footnotetext{
21 Importante observer que o termo liberal em inglês é mais comumente utilizado para designar adepto de idéias progressistas e de valorização dos direitos individuais, diferente do termo em português que se refere ao liberalismo ou ao neo-liberalismo econômico.

22 Original completo: "It's a different type of racist. Now, I remember one night I was at a fundraiser for President Obama, a lot of you were there. And you know it's me and all of Hollywood. It's all of us there and about four black people. Me. Let's see. Quincy Jones. Russell Simmons. Questlove. You know, the usual suspects. You know and every black actor that wasn't working. Needless to say Kev Hart was not there. So at some point you get to take a picture with the President. And they're setting up the picture. You get like a little moment with the President. I'm like, 'Mr. President, you see all these writers and producers, actors, they don't hire black people. And they're not nicest white people on earth. They're liberals.' Cheese". (Idem).
} 
ECO, Umberto. Obra aberta: forma e indeterminação nas poéticas contemporâneas. São Paulo: Perspectiva, 2008.

ENWEZOR, Okwui. Reframing the Black Subject: Ideology and Fantasy in Contemporary South African Representation. In: PINDER, Kymberly (Org.). Race-ing Art History. Nova Yorque: Routledge, 2002.

GILROY, Paul. O Atlântico Negro: modernidade e dupla consciência. São Paulo: Ed.34, 2001.

HALL, Stuart. The Spectacle of the 'Other'. In: Representation: Cultural Representations and Signifying Practices. London: Sage/Open University, 1997.

HALL, Stuart. The West and the Rest: Discourse and Power. In: HALL, Stuart; GIEBEN, Bram. Formations of Modernity. Cambrigde: Blackwell, 1995. pp. 276-333.

HALL, Stuart. The work of representation. In: HALL, Stuart (org.) Representation: Cultural representation and cultural signifying practices. London/Thousand Oaks/New Delhi: Sage/Open University, 1997b.

JOHNSON, Anna. Coco Fusco and Guillermo Gómez-Peña. BOMB Magazine, New York, 14 mai. 2013.

KRUEGER, Anton. Gazing at Exhibit A: Interview with Brett Bailey. In: Liminalities: A Journal of Performance Studies. Vol. 9, N. 1, February 2013

MEMMI, Albert. Portrait du colonisé précédé de Portrait du colonisateur. Paris: Gallimard, 2012.

SIEG, Katrin. Towards a Civic Contract of Performance: Pitfalls of Decolonizing the Exhibitionary Complex at Brett Bailey's Exhibit B 1. In: Theatre research international [0307-8833] vol:40 fasc:3, 2015, pp. 250-271.

\section{Audiovisual}

META TV. L'exposition scandaleuse - Rassemblement Anti-Exhibit B. Disponível em: $<$ http://www.dailymotion.com/video/x2c1ypq_l-exposition-scandaleuse-rassemblement-anti-exhibit-b-meta-tv_tv?start=335> Acesso em: 10 mar. 2015.

\section{Fontes}

BLANCHARD, Pascal. Exhibit B force à voir le racisme les yeux dans les yeux. Entrevista concedida a Caroline Châtelet. In : Regards.fr , 1 dez. 2014. Disponível em: <http:// 
www.regards.fr/web/article/pascal-blanchard-exhibit-b-force-a> Acesso em: 01 mar. 2016.

BOUCHEZ, Emmanuelle. "Exhibit B", histoire d'une exposition anticoloniale... taxée de racisme. Télérama, Paris, 26 de nov. 2014. Disponível em: < http://www.telerama.fr/scenes/exhibit-b-histoire-d-une-exposition-anticoloniale-taxee-de-racisme,119806.php> Acesso em: 12 mar. 2015.

FABRE, Clarisse. Guillaume Mivekannin, esclave dans "Exhibit B": "Le voyeur n'est pas celui qu'on pense". (Publicado em 12.12.2014 à 09h37). Disponível em:

http://www.lemonde.fr/scenes/article/2014/12/12/guillaume-mivekannin-esclavedans-exhibit-b-le-voyeur-n-est-pas-celui-qu-on-pense_4539381_1654999.html último acesso em 11 mar. 2015

FIORETTI, Gustavo. Com programação reduzida, Mostra de Teatro de SP terá racismo como tema. Folha de São Paulo, São Paulo, 2 de fev. 2016. Disponível em:

<http://www1.folha.uol.com.br/ilustrada/2016/02/1735898-com-programacao-reduzida-mostra-de-teatro-de-sp-tera-racismo-como-tema.shtml> Acesso em: 28 fev. 2016.

FIORETTI, Gustavo. Antes de cancelar peça acusada de racismo, mostra propôs troca a autor. Folha de São Paulo, São Paulo, 19 de fev. 2016. Disponível em: < http:// www1.folha.uol.com.br/ilustrada/2016/02/1740795-mitsp-propos-trocar-peca-acusada-de-racismo-antes-de-cancelar-realizacao.shtml> Acesso em: 28 fev. 2015.

PEREIRA, Elsa. Exhibit B. Time Out, Paris. Disponível em:

<https://www.timeout.fr/paris/spectacle/theatre/exhibit-b> Acesso em: 10 mar. 2015.

ROCK, Chris. Opening Monologue at the 2016 Oscars. [OSCAR 2016. 88. a cerimônia de entrega dos Academy Awards da Academia de Artes e Ciências Cinematográficas]. Los Angeles: ABC, 28 de fevereiro de 2016. Disponível em: < http://oscar.go.com/ news/oscar-news/chris-rock-opening-2016-oscars>. Último acesso em 8 nov. 2016.

SOPO, Dominique. Exhibit B: le révélateur d'un malaise. Huffington Post, Paris, 10 dez. 2014. Disponível em: http://www.huffingtonpost.fr/dominique-sopo/exhibit-b -le-revelateur-d_b_6292906.html Acesso em: 12 mar. 2015.

ULESKI, Serge. Exhibit $B$ : quand la représentation du racisme se prend pour de l'anti -racisme. 16 de dez. 2014. Disponível em: <http://sergeuleski.blogs.nouvelobs.com/ archive/2014/12/14/exhibit-b-quand-la-representaiton-du-racisme-se-prend-pour-de-l-anti-racism.html>. Acesso em: 10 mar. 2015.

Recebido em: 30/09/2016

Aprovado em: 13/11/2016 